\title{
EDUCAÇÃO AMBIENTAL EM TEMPOS DE COVID-19: PROCESSOS E PRODUTOS DA INTERAÇÃO REMOTA ASSÍNCRONA
}

\section{ENVIRONMENTAL LITERACY DURING COVID-19 PANDEMIC: ACTIVITIES AND OUTCOME OF THE REMOTE ASYNCHRONOUS INTERACTION}

\author{
Leandro Bordin* \\ ORCID: https://orcid.org/0000-0002-4703-6671 \\ Thays Regina Miotto Begnini** \\ ORCID: https://orcid.org/0000-0002-9423-9084 \\ Rodrigo Dal Bosco Fontana*** \\ ORCID: https://orcid.org/0000-0002-8835-7447 \\ Graziele Moura Borges Silva**** \\ ORCID: https://orcid.org/0000-0001-7008-1094
}

\section{Resumo}

O artigo apresenta o projeto de extensão "Educação Ambiental: conscientização para a construção de futuros", desenvolvido por professores e estudantes de Engenharia Ambiental e Sanitária junto ao Programa Social "Viver Ações Sociais", no município de Chapecó, Santa Catarina. No texto, são apresentados os processos e os produtos audiovisuais da interação remota assíncrona - imposta pela disseminação e contaminação da COVID-19 - com um grupo de crianças com idades entre 6 e 10 anos, no período de março a agosto de 2020. O percurso metodológico participativo e colaborativo - de definição e construção dos conteúdos estruturou as discussões em torno dos seguintes temas: (a) cuidados com o meio ambiente, (b) resíduos sólidos e reciclagem, (c) recurso natural água, e (d) energias renováveis. Apesar das dificuldades tecnológicas, os resultados demonstram importantes compreensões acerca da conscientização ambiental, da ampliação dos conhecimentos e do desenvolvimento de um pensamento crítico acerca dos temas propostos.

Palavras-chave: Consciência ambiental, Formação cidadã, Ciência, Tecnologia e Sociedade (CTS).

Data recebimento: $08 / 04 / 2021$

Data de aceite: $12 / 08 / 2021$

\begin{abstract}
This paper presents the outreach project "Environmental Education: raising awareness about the future" carried out by environmental engineering professors and students in partnership with the social program "Viver Ações Sociais" developed in Chapecó, Santa Catarina, Brazil. The text describes the activities and audiovisual products of asynchronous remote interaction - an imposition of the spread and contamination of COVID-19 - with a group of children aged between 6 and 10, conducted from March to August 2020. The methodological strategies - participative and collaborative - for the definition and structuration of content led to discussions in the following themes: (a) caring for the environment, (b) waste and recycling, (c) natural water resource and (d) renewable energies. Despite the technological difficulties, the results demonstrate the increasing understanding of the environmental awareness, the improvement of knowledge and the development of critical thinking related to these themes.
\end{abstract}

Keywords: Environmental awareness; Citizenship education; Science, Technology and Society (STS).

* Professor da Universidade Fronteira Sul (UFFS), Chapecó - SC, Brasil. Doutorado em Educação Científica e Tecnológica. E-mail: lbordin@uffs.edu.br

** Aluno de Graduação da Universidade Fronteira Sul (UFFS), Chapecó - SC, Brasil. E-mail: thaysrmiotto@gmail.com

*** Professor da Universidade Fronteira Sul (UFFS), Chapecó - SC, Brasil. Doutorado em Física. E-mail: rodrigo.fontana@uffs.edu.br

**** Aluno de Graduação da Universidade Fronteira Sul (UFFS), Chapecó - SC, Brasil. E-mail: grazielemourab@gmail.com 


\section{Introdução}

O número crescente de problemas ambientais gerados pelo desenvolvimento tecnológico e econômico constantemente nos alerta para o fato de que a preservação dos recursos naturais e da manutenção da vida humana em comunidade dependem, também, da promoção de uma cultura de educação para o meio ambiente.

A Educação Ambiental (EA) pode ser entendida como aquela em que cada cidadão toma para si, ao mesmo tempo que compartilha com a coletividade, a responsabilidade pela construção de valores e atitudes socioambientais por meio de conhecimentos, habilidades, atitudes e competências voltadas para a conservação do meio ambiente (BRASIL, 1999).

Desse entendimento deriva que a problematização das questões ambientais está sempre revestida de um caráter social, político e econômico de expressiva magnitude e, desta forma, precisa ser discutida sob a ótica de sua interdisciplinaridade. Compreendemos, nesse contexto, que, para além da busca de soluções tecnológicas para os problemas (socio)ambientais, a Engenharia tem papel fundamental, também, no âmbito da EA.

Neste ponto, cabe ressaltar a importância da EA na esfera da educação superior e na sua especificidade para o campo das Engenharias. O Decreto $n^{\circ} 4.281$, de 25 de junho de 2002,elaborado e publicado com o objetivo de regulamentar a Lei $\mathrm{n}^{0}$ 9.795, de 27 de abril de 1999 - torna obrigatória a inclusão da EA em todos os níveis e modalidades de ensino (BRASIL, 2002). Tal direcionamento indica que as ações mitigatórias para os problemas ambientais são responsabilidades de todas as profissões e de todos os cidadãos. Tais publicações também passam a orientar a formação e a atuação dos profissionais de Engenharia numa ótica de interação e integração entre aspectos técnicos e ambientais.

Considerando os elementos supracitados, um coletivo de estudantes e professores do curso de Engenharia Ambiental e Sanitária do campus Chapecó/SC da Universidade Federal da Fronteira Sul (UFFS) desenvolveu, nos anos de 2018, 2019 e 2020, ações de extensão no âmbito do projeto denominado "Educação Ambiental: conscientização para a construção de futuros". O projeto atendeu, anualmente, cerca de 40 crianças inscritas no Programa Social "Viver Ações Sociais", localizado no município de Chapecó.

Criado no ano de 1993, o Viver é uma entidade sem fins lucrativos que atende diáriamente 150 crianças e adolescentes em situação de vulnerabilidade social, através de atividades em contraturno escolar. Seu propósito, fundamentado na missão de promover o acesso aos direitos sociais do indivíduo, contempla a participação de crianças e adolescentes em atividades socioeducativas, esportivas, culturais e recreativas, além de oferecer acompanhamento psicossocial. Convém destacar que o Programa Viver atua com ações complementares, como o Grupo de mulheres e mães, e no período noturno, em parceria com outras instituições, oferta aulas de Ensino Fundamental, Médio e Técnico para jovens e adultos. Neste contexto - social - e devido ao compromisso público e popular da Universidade Federal da Fronteira Sul, verificou-se, junto ao Programa Viver, a oportunidade de interação com a comunidade local, por meio das crianças participantes do Programa. 
As ações discutidas neste artigo tratam do período de distanciamento físico/social impostos pela disseminação e contaminação da COVID-19. No mês de março de 2020 começamos o trabalho com 40 crianças, com idade entre 6 e 10 anos, divididas em duas novas turmas, com dois encontros presencias - periodicidade semanal com tempo de duração de 45 minutos cada turma - e logo na semana subsequente, as atividades presenciais foram suspensas. O desafio naquele momento foi então reorganizar as atividades e pensar estratégias para que a construção dos principais temas inicialmente planejados para o semestre letivo pudesse ser mantida.

Neste contexto, o presente artigo objetiva apresentar e discutir os processos e os produtos da interação remota assíncrona com as crianças. O percurso metodológico utilizou, como elementos disparadores para as atividades, animações (de domínio público) acompanhadas de perguntas que deveriam ser respondidas pelo conjunto de crianças, por meio de desenhos, áudios e textos. O tratamento dos dados foi feito usando a metodologia de Análise de Conteúdo e as categorias emergentes indicaram temas que foram aprofundados através de materiais áudiovisuais devolutivos. O processo - participativo e colaborativo - de definição e construção dos conteúdos estruturou a produção de materiais audiovisuais em torno dos seguintes temas: (a) cuidados com o meio ambiente, (b) resíduos sólidos e reciclagem, (c) recurso natural água, e (d) energias renováveis.

\section{A Educação Ambiental na construção coletiva da cidadania}

A Política Nacional de Educação Ambiental orienta um enfoque interdisciplinar para os processos educativos da área, tendo como destaque os seguintes objetivos (BRASIL, 1999):

a) O desenvolvimento de uma compreensão integrada do meio ambiente em suas múltiplas e complexas relações.

b) O estímulo e o fortalecimento de uma consciência crítica sobre a problemática ambiental e social.

c) O incentivo à participação individual e coletiva, permanente e responsável, na preser-vação do equilíbrio do meio ambiente.

d) $\mathrm{O}$ fomento e o fortalecimento da integração com a ciência e a tecnologia.

e) $\mathrm{O}$ fortalecimento da cidadania, autodeterminação dos povos e solidariedade como fundamentos para o futuro da humanidade.

Com base em tais direcionamentos,

Entende-se por Educação Ambiental os processos por meio dos quais o indivíduo e a coletividade constroem valores sociais, conhecimentos, habilidades, atitudes e competências voltadas para a conservação do meio ambiente, bem de uso comum do povo, essencial à sadia qualidade de vida e sua sustentabilidade. A Educação Ambiental é um componente essencial e permanente da educação nacional, devendo estar presente, de forma articulada, em todos os níveis e modalidades do processo educativo, em caráter formal e não-formal (BRASIL, 1999, p.1). 
Ramos (2001) destaca que a expressão ‘educação ambiental', desde a década de 1970, ganha espaço não apenas no campo político, mas nos mais diferentes contextos pedagógicos. No lócus do cenário educacional, a EA se apresenta servindo de suporte teórico e (socio) técnico às atividades que se desenvolvem na área. Isso se dá (ou, idealmente dar-se-ia) por meio do constante diálogo com as diferentes esferas - sociais, políticas e econômicas, por exemplo - que integram a busca por soluções individuais e coletivas, no intuito de minimizar os impactos ambientais causados pela ação antrópica.

Nessa direção, Sorrentino et al. (2005) discutem a estreita relação entre EA e educação para a cidadania, na medida em que orientam que a superação das causas estruturais e conjunturais dos problemas ambientais passa pela construção, por meio da educação, de um sentido de pertencimento e corresponsabilidade. Para Loureiro (2004), a definição de Educação Ambiental também está vinculada ao exercício da cidadania, uma vez que estabelece um movimento unitário entre teoria e prática, integra a mudança de padrões cognitivos com ação política democrática e mudança de valores, e reestrutura o conjunto das relações sociais e econômicas que definem a base de organização da vida humana em sociedade.

Diante do exposto, é necessário esclarecer que a EA tratada neste trabalho/projeto é aquela por meio da qual se constrói uma responsabilidade coletiva pela prevenção e resolução de problemas socioambientais. É o que orienta Guimarães (2004): a EA deve ser entendida como uma educação crítica que direciona transformações nas relações de produção, nas relações sociais e, em síntese, nas implicações políticas, econômicas, sociais e ambientais das/nas relações entre os seres humanos e a natureza.

A necessidade de envolver a sociedade civil por meio da conscientização - educação ambiental é discurso recorrente em trabalhos que versam sobre questões ambientais. Destacamse, neste ponto, também os trabalhos de Medeiros et al. (2011), França e Guimarães (2014), Bianchini et al. (2015), Silva et al. (2015), Hansen (2018) e Moitinho (2017), que, por meio de discussões teóricas e de intervenções práticas, em diferentes tempos e espaços, destacam o papel da EA na formação de cidadãos conscientes das múltiplas facetas que contemplam a vida em sociedade.

Alves (2001), ao discutir a estreita relação entre educação para a cidadania e EA, destaca que a relação dos cidadãos com a cidade (sociedade) e seus múltiplos problemas com ênfase aqui para as questões ambientais - passa por algumas fases (Quadro 1) que são impulsionadas, em grande medida, por processos educativos formais ou não-formais. 
Quadro 1 - Fases da educação para cidadania e sua relação com a educação ambiental

\begin{tabular}{|c|l|}
\hline $\begin{array}{c}\text { Sensibilização/Tomada de } \\
\text { consciência }\end{array}$ & $\begin{array}{l}\text { O processo de tomada de consciência pode ser fruto de uma capacidade } \\
\text { crítica e avaliativa própria ou ser fruto de ações de sensibilização, integradas } \\
\text { ou não, em experiências de caráter educativo formal; essa fase constitui o } \\
\text { despertar para a ação. }\end{array}$ \\
\hline $\begin{array}{c}\text { Conhecimento/Apropriação } \\
\text { Reflexão/Questionamento/ } \\
\text { Problematização }\end{array}$ & $\begin{array}{l}\text { Uma vez recebida a informação/conhecimento que sirva de substrato para } \\
\text { uma tomada de posição, minimamente fundamentada, o cidadão começa a } \\
\text { assumir o problema como seu. }\end{array}$ \\
\hline $\begin{array}{c}\text { (4) } \\
\text { merecedor de uma ponderação; começam a surgir questões; outros problemas } \\
\text { começam a ser identificados. }\end{array}$ \\
\hline $\begin{array}{c}\text { Posicionamento/Verbalização e } \\
\text { audição dos outros }\end{array}$ & $\begin{array}{l}\text { A fundamentação obtida permite a tomada de posição; esta deve ser expressa } \\
\text { (comunicada) no âmbito da - de uma - coletividade; a representação } \\
\text { individual é importante, mas o processo mais significativo é o de partilha, de } \\
\text { construção coletiva. }\end{array}$ \\
\hline $\begin{array}{c}\text { Participação democrática e } \\
\text { Intervenção cívica }\end{array}$ & $\begin{array}{l}\text { O cidadão age conscientemente no sentido da intervenção/ação; o cidadão se } \\
\text { sente apropriado da questão/problema - ambiental, por exemplo - e pela via } \\
\text { da participação democrática é 'chamado' a se envolver nos processos de } \\
\text { decisão }\end{array}$ \\
\hline
\end{tabular}

Fonte: Alves (2001)

No alinhamento com os trabalhos supracitados, cogitamos que a discussão e entendimento das implicações sociais, políticas, econômicas e ambientais - educação para a cidadania - do desenvolvimento tecnológico pode ser feita, também, pela via da EA. Isso tanto para os estudantes formadores (neste caso, de engenharia), que precisam compreender interdisciplinarmente os temas de discussão, como para as crianças em formação.

A respeito da EA para crianças das séries iniciais, Medeiros et al. (2011), Bianchini et al. (2015) e Hansen (2018) destacam a importância de o processo de ensino-aprendizagem ser construído por meio das vivências dos estudantes e dos fenômenos que ocorrem à sua volta, buscando apoiá-los, com o auxílio dos conceitos científicos pertinentes. Além disso, orientam que as atividades teóricas partam de uma abordagem lúdica, a fím de despertar o interesse, e evoluam para atividades práticas, com o intuito de provocar o posicionamento crítico e estimular possíveis intervenções/ações.

Todos os trabalhos aqui referenciados, em especial o desenvolvido por França e Guimarães (2014), destacam que as ações de EA promovem mudanças de comportamento e despertam nos estudantes o interesse de encontrar soluções para as problemáticas ambientais. Isso pode ser percebido de diferentes formas, que vão desde a capacidade de disseminar informações sobre tais temas até a mudança de práticas individuais e coletivas frente aos problemas do entorno. As autoras destacam, também, que as ações de EA precisam ser constantes no âmbito da escola - caracterizando a EA como eixo transversal na/da formação - e que avanços significativos ainda precisam ser feitos no que concerne ao envolvimento dos 
pais, da comunidade e do poder público em ações e planos voltados à preservação do meio ambiente, despertando, dessa forma, a conscientização para a ação e a busca de soluções coletivas - concretas para os problemas ambientais - etapas 4 e 5 caracterizadas por Alves (2001) e descritas no Quadro 1.

\section{Metodologia de trabalho e de produção de materiais educativos}

As atividades do projeto "Educação Ambiental: conscientização para a construção de futuros" iniciaram em modo presencial em março de 2020. Os extensionistas - um professor coordenador/orientador, um professor colaborador, uma estudante bolsista e outra voluntária - usaram os dois primeiros encontros semanais para conhecer as duas turmas, estabelecer as primeiras relações e construir entendimentos básicos sobre os objetivos da EA, sobre os conteúdos que seriam trabalhados e sobre a metodologia de trabalho. O objetivo dessa fase inicial foi o de despertar o interesse pelo tema e pelas dinâmicas que seriam trabalhadas ao longo do semestre.

$\mathrm{Na}$ terceira semana letiva, as atividades presenciais foram suspensas por orientações institucionais, municipais e estaduais. O otimismo inicial de que se teriam apenas poucas semanas de afastamento deu lugar a um quadro de suspensão por tempo indeterminado, o que levou a se questionar a continuidade do projeto. Naquele momento, não havia recursos tecnológicos disponíveis para a continuação do trabalho com a maioria das 40 crianças que estavam inscritas no projeto. Aqui cabe ressaltar, mais uma vez, que o Programa Viver atende crianças em situação de vulnerabilidade social e, portanto, as possibilidades de acesso às atividades remotas, tanto da escola regular como do Programa, ficaram dificultadas.

Em reunião com a equipe diretiva e pedagógica do Viver, vislumbrou-se como única possibilidade o trabalho remoto assíncrono, via aplicativo de mensagens, usando o aparelho celular das mães, pais e responsáveis. Fez-se, então, um primeiro movimento de aproximação e de engajamento, enviando para o grupo uma animação disponível na internet que tratava sobre os cuidados para evitar a contaminação e a disseminação do coronavírus, e percebeuse que a interação foi bastante positiva.

Neste ponto do trabalho, as duas turmas foram juntadas em um único grupo e os conteúdos e as estratégias de trabalho foram redimensionados. Seguindo as orientações de Medeiros et al. (2011) e Bianchini et al. (2015), havia ainda mais certeza de que as atividades no formato remoto deveriam partir, via de regra, de uma abordagem lúdica, pautada nas vivências dos estudantes e nos fenômenos que ocorrem à sua volta e que, portanto, tivessem um sentido em seu cotidiano.

Assim, todas as interações assíncronas, ocorridas no período de abril a agosto de 2020, tiveram como elemento disparador uma animação selecionada da internet. Contando com a mediação das mães, pais e responsáveis, era lhes enviado um conjunto pequeno de perguntas para que as crianças respondessem por meio de desenhos, áudios ou textos. De posse das 
respostas, usando a metodologia de Análise de Conteúdo, eram selecionadas as categorias que, no âmbito da temática do momento, precisavam de novos entendimentos e construções.

A Análise de Conteúdo conduz um percurso organizado do qual emergem novas compreensões e entendimentos sobre o fenômeno estudado. Ao se evidenciarem as relações entre o conteúdo dos desenhos, áudios e textos, a construção teórica acerca do tema estudado e o planejamento inicialmente traçado, foi possível identificar convergências e divergências por meio dos elementos mais representativos do conjunto - unidades de análise - e, então, destacar categorias emergentes. Tais categorias constituíram os principais elementos de problematização, discussão e construção sobre a temática (BARDIN, 1977; MORAES, 1999).

A devolutiva para as crianças era feita por meio de áudio e, principalmente, de áudiovisuais (confeccionados através do software videomaker), nos quais se intercalavam recortes de falas, desenhos e textos recebidos como resposta às questões, e novas explicações da estudante de engenharia responsável pela condução do projeto, acrescidas de imagens que ilustravam didaticamente tais explicações. Assim, quem direcionava a construção dos temas era o material que as crianças devolviam: eram os seus entendimentos iniciais sobre a temática que davam o rumo dos conteúdos a serem aprofundados.

Nesse novo contexto, o objetivo continuava claro: o processo participativo e colaborativo na definição e construção dos conteúdos tinha como mote a conscientização ambiental, a ampliação dos conhecimentos e o desenvolvimento de um pensamento crítico acerca dos temas propostos - fases 1, 2 e 3, caracterizadas por Alves (2001) e descritas no Quadro 1.

\section{Processos e produtos da interação com as crianças}

Uma vez estabelecido o engajamento das mães, pais e responsáveis, a primeira atividade foi a definição de temas ambientais que despertassem a curiosidade e que tivessem um significado para o grupo de crianças. Nesse sentido, o elemento disparador para a primeira atividade se deu pela socialização de uma animação infantil a respeito do Dia do Planeta Terra (22 de abril). Nesta atividade, as crianças deveriam assistir ao vídeo enviado e responder, por meio de um desenho, a pergunta: "O que você faz ou pode fazer para cuidar do planeta Terra?". A partir dos desenhos, determinou-se a necessidade de discussão e aprofundamento de três temas: (a) Resíduos sólidos e reciclagem, (b) Recurso natural água, e (c) Energias renováveis. A definição dos temas foi feita utilizando-se os princípios da metodologia de Análise de Conteúdo e se deu, neste caso, por meio da identificação das recorrências nos desenhos, conforme Quadro 2. 
Quadro 2 - Processo de análise e categorização das respostas do tema "Cuidados com o Planeta Terra"

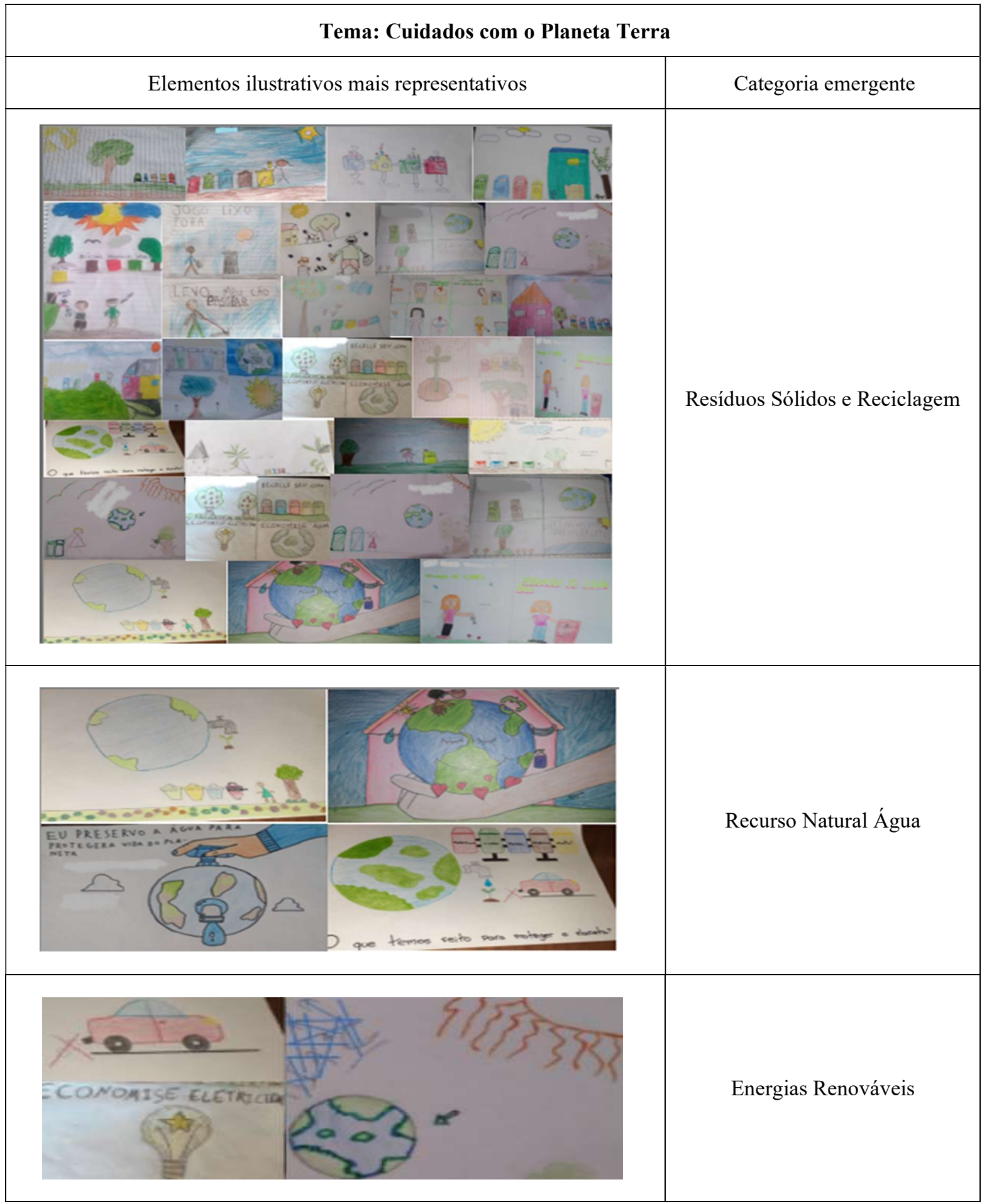

Fonte: Dos autores 
Motivados pela participação das crianças até este ponto, deu-se sequência nos trabalhos, buscando-se, agora, o aprofundamento do tema de Resíduos sólidos e reciclagem, primeira categoria do Quadro 2, por meio do envio de uma animação que abordava, dentre outros, os conceitos de 'lixo', rejeito e aterro sanitário.

Foi solicitado, então, que as crianças respondessem, através de áudios, duas perguntas relacionadas ao tema em questão: (1) Que tipo de resíduos orgânicos e que tipo de resíduos recicláveis são produzidos em casa? e (2) Qual o destino dado para eles?

A análise das transcrições dos áudios permitiu categorizar as respostas e definir possibilidades de novas explicações/construções sobre o tema em questão. O Quadro 3 sintetiza as categorias que foram discutidas no áudio, que foi editado para ser devolvido às crianças.

Quadro 3 - Processo de análise e categorização das respostas do tema "Resíduos sólidos e reciclagem"

\begin{tabular}{|c|c|}
\hline \multicolumn{2}{|l|}{ Tema: Resíduos sólidos e reciclagem } \\
\hline Elementos/expressões mais representativos & Categoria emergente \\
\hline $\begin{array}{l}\text { “Aqui em casa temos dois lixeiros: um orgânico e um reciclável. No orgânico } \\
\text { colocamos restos de frutas e cascas de alimentos. No reciclável, colocamos } \\
\text { papel e plástico". } \\
\text { "Eu tenho dois lixos, um para papel, vidro e plástico. O outro é de comida e } \\
\text { cascas de banana". } \\
\text { "Aqui em casa nós temos dois lixos: um para plástico e papéis e outro para } \\
\text { restos de comida, restos de cascas de legumes e frutas". } \\
\text { "No orgânico eu coloco restos de comida, cascas de legume, banana, tudo que } \\
\text { tem a ver com comida. No reciclável eu coloco plástico, caixinha de leite e papel”. } \\
\text { "No reciclável colocamos plástico, papel, caixa de leite e lata". } \\
\text { "Os resíduos recicláveis são papel, plástico, metal, vidro e alumínio". } \\
\text { "De lixo reciclável, nós temos papel, plástico, vidro, caixa de leite". }\end{array}$ & $\begin{array}{l}\text { Valorização da acertada } \\
\text { classificação de resíduos } \\
\text { orgânicos e recicláveis e } \\
\text { esclarecimento sobre } \\
\text { resíduos especiais, com } \\
\text { destaque para "lixo } \\
\quad \text { eletrônico" }\end{array}$ \\
\hline $\begin{array}{l}\text { "Eu separo esses lixos e coloco cada um em um tipo de lixo diferente”. } \\
\text { "Os recicláveis, que são plásticos, vidros e papéis, lavamos e destinamos ao } \\
\text { reciclável”. } \\
\text { "Eu reciclo meu lixo orgânico, papel, plástico e vidro". } \\
\text { "Aqui em casa nós separamos os resíduos e damos o destino correto para eles". } \\
\text { "Separamos e colocamos cada um no seu dia para o lixeiro pegar". }\end{array}$ & $\begin{array}{l}\text { Cuidados com a } \\
\text { reciclagem e informações } \\
\text { sobre a coleta seletiva }\end{array}$ \\
\hline $\begin{array}{l}\text { "O reciclável é quando a gente pode reciclar. A gente pode reciclar tudo que achar. } \\
\text { Um negócio meu que eu usava, eu transformei em uma garrafinha de água". } \\
\text { "Eu posso fazer alguma coisa, um bonequinho, com as coisas recicláveis". } \\
\text { "Podemos fazer muitas coisas com o lixo reciclável, inclusive brinquedos e acessórios". }\end{array}$ & $\begin{array}{l}\text { (Re)aproveitamento de } \\
\text { resíduos recicláveis }\end{array}$ \\
\hline $\begin{array}{l}\text { "Separamos os lixos orgânicos, que são cascas de frutas e restos de comida e } \\
\text { destinamos para a compostagem". } \\
\text { "No lado da minha casa temos uma horta e lá jogamos nosso lixo orgânico". } \\
\text { "Todo o orgânico colocamos na nossa horta". } \\
\text { "Usamos o orgânico para adubar na nossa horta". }\end{array}$ & $\begin{array}{l}\text { (Re)aproveitamento dos } \\
\text { resíduos orgânicos para } \\
\text { compostagem }\end{array}$ \\
\hline
\end{tabular}

Fonte: Dos autores 
Em linhas gerais, o áudio devolutivo valorizou, num primeiro momento, as contribuições das crianças e os 'acertos' na classificação dos resíduos orgânicos e recicláveis. No entanto, os elementos mais representativos da primeira categoria emergente revelaram a falta de compreensão acerca dos resíduos considerados especiais. Sendo assim, foi construída uma explicação em torno, principalmente, dos resíduos eletrônicos (pilhas, baterias, equipamentos e afins), informando pontos específicos de coleta na cidade de Chapecó.

A definição da segunda categoria de discussão direcionou uma interlocução acerca dos cuidados na separação dos resíduos recicláveis para posterior reciclagem e sobre informações da coleta seletiva que acontece no bairro. A terceira categoria valorizou e destacou a reutilização de materiais recicláveis e a produção de brinquedos a partir destes. Essa categoria, em específico, despertou o interesse dos extensionistas para a realização de uma oficina de brinquedos numa oportunidade presencial futura. Por fim, o debate que emergiu da terceira categoria foi a valorização e a construção de orientações técnicas acerca da compostagem de resíduos orgânicos.

$\mathrm{Na}$ intervenção seguinte, foi mantido o mesmo modelo de interação com as crianças, sendo enviadas duas animações sobre o recurso natural água. Como atividade de devolução, foi solicitado que as crianças respondessem três questões: (1) De onde vem a água que é utilizada em casa? (2) Para que e de que forma é utilizada? (3) Tem algum exemplo de reutilização e economia de água para nos contar? As respostas poderiam ser enviadas por meio de áudios ou textos. Novamente, a análise dos textos e da transcrição dos áudios permitiu categorizar as falas/ experiências das crianças e fazer interlocuções em um vídeo devolutivo, utilizando-se as categorias sintetizadas no Quadro 4.

Quadro 4 - Processo de análise e categorização das respostas do tema "Recurso natural água"

\begin{tabular}{|c|c|}
\hline \multicolumn{2}{|l|}{ Tema: Recurso natural água } \\
\hline Elementos/expressões mais representativos & Categoria emergente \\
\hline $\begin{array}{l}\text { “A água vem da natureza, a gente cuida e não esbanja”. } \\
\text { "A água das nossas casas vem dos rios". } \\
\text { "A água vem da chuva". } \\
\text { "A água vem do poço artesiano, que pela tubulação chega na nossa casa". } \\
\text { "A água vem do poço". } \\
\text { "A água que vem aqui em casa é da Casan [Companhia de água e saneamento de } \\
\text { Santa Catarina]". }\end{array}$ & $\begin{array}{l}\text { Origem da água: ciclo } \\
\text { hidrológico }\end{array}$ \\
\hline $\begin{array}{l}\text { "Nós usamos para nossa higiene, fazer comida, beber, lavar as roupas e limpar a } \\
\text { casa". } \\
\text { "Eu uso a água para tomar banho, escovar os dentes, lavar meu rosto, molhar } \\
\text { meu cabelo e tomar". } \\
\text { "É utilizada para fazer comida, tomar banho, limpar a casa, entre outros". } \\
\text { "Utilizamos para tomar banho, beber, molhar as plantas e cozinhar". }\end{array}$ & $\begin{array}{l}\text { Usos da água: importância } \\
\text { da água para a sobrevi- } \\
\text { vência humana e das } \\
\text { demais espécies }\end{array}$ \\
\hline $\begin{array}{l}\text { “Eu reutilizo a água da máquina que a gente lava a roupa pra lavar o carro e a } \\
\text { calçada da rua". } \\
\text { "Quando chove, usamos a água da chuva para limpar a área”. }\end{array}$ & $\begin{array}{l}\text { Uso racional da água: } \\
\text { valorização e estímulo à } \\
\text { reutilização }\end{array}$ \\
\hline $\begin{array}{l}\text { "Nós não podemos jogar lixo nas nascentes dos rios. Economizar o máximo } \\
\text { possível para nós não ficarmos sem água no futuro, porque já está faltando hoje } \\
\text { em dia, porque sem água não há vida”. } \\
\text { Não é pra deixar a torneira ligada e quando for tomar banho é pra tomar rapidinho". }\end{array}$ & $\begin{array}{l}\text { Preservação da água e } \\
\text { cuidados com o } \\
\text { desperdício }\end{array}$ \\
\hline
\end{tabular}

Fonte: Dos autores 
O vídeo produzido apresentou, em um primeiro momento, a contribuição das crianças acerca da origem da água, fazendo-se a interlocução entre o ciclo hidrológico e o ‘caminho’ da água até chegar nas residências. A segunda categoria apresentou os usos da água no cotidiano, bem como sua importância para a sobrevivência de todas as espécies. A terceira categoria apontou o uso racional da água, de modo a valorizar e estimular a reutilização desse recurso natural. Por fim, a quarta categoria permitiu destacar as falas das crianças acerca da preservação e do uso consciente da água, incentivando os cuidados com o desperdício e com a não contaminação/ poluição.

No último tema, sobre energias renováveis, foram enviadas duas animações que abordavam os tipos de energias existentes, bem como suas vantagens e desvantagens. Também foram requisitadas respostas à três perguntas: (1) A energia elétrica que chega na sua casa é gerada pela água (hídrica), pelo Sol (solar) ou pelo vento (eólica)? (2) Considerando a natureza e o clima da região de Chapecó, que outro tipo de energia poderia ser gerado para abastecer nossas casas? Nos diga por que você deu esta resposta. (3) Você já viu ou sabe onde têm parques eólicos (grandes cata-ventos) para geração de energia do vento?

Assim como na atividade sobre a água, produziu-se um vídeo de devolução com explicações e intervenções, com foco nas energias hídrica, solar e eólica, de modo a esclarecer a trans-ormação da energia proveniente de fontes naturais e a sua conversão e distribuição em forma de energia elétrica. A definição das interlocuções feitas na montagem do audiovisual se deu pela transcrição e análise dos áudios, conforme Quadro 5.

Quadro 5 - Processo de análise e categorização das respostas do tema "Energias renováveis"

\begin{tabular}{|c|c|}
\hline \multicolumn{2}{|l|}{ Tema: Energias renováveis } \\
\hline Elementos/expressões mais representativos & Categoria emergente \\
\hline $\begin{array}{l}\text { "A nossa energia é gerada pela força da água”. } \\
\text { "A nossa energia vem da água”. } \\
\text { "A energia elétrica que vem aqui em casa é gerada pela água que é gerada pelas } \\
\text { barragens". } \\
\text { "A energia que vem na nossa casa é elétrica, da hidrelétrica da Foz do Chapecó". } \\
\text { "A energia que chega até a minha casa é gerada através da água dos rios da } \\
\text { nossa região, que tem pequenas usinas hídricas". }\end{array}$ & $\begin{array}{l}\text { Principal origem da energia } \\
\text { elétrica da região: o } \\
\text { funcionamento das usinas } \\
\text { hidrelétricas }\end{array}$ \\
\hline $\begin{array}{l}\text { "Pelo clima de Chapecó, poderíamos também ter energia solar". } \\
\text { "Aqui em Chapecó pode também ser gerada por placas solares". } \\
\text { "Eu já vi perto da casa do meu pai placas solares que geram energia". } \\
\text { "Outra forma que a energia poderia vir até a minha casa seria através do sol, } \\
\text { com painéis solares". } \\
\text { "A gente poderia usar placas solares, então a gente poderia colocar em cima } \\
\text { dos nossos tetos e depois usar aquela". }\end{array}$ & $\begin{array}{c}\text { O Sol como fonte de } \\
\text { energia: energia solar } \\
\text { fotovoltaica e energia solar } \\
\text { térmica }\end{array}$ \\
\hline $\begin{array}{l}\text { "Eu já vi um parque eólico em Bom Jardim da Serra”. } \\
\text { "Eu nunca fui a um parque que tem cata-vento, eu só vi um na empresa [cita o } \\
\text { nome] aqui perto da nossa casa". } \\
\text { "Já vi de longe os cata-ventos em Rio Grande e na cidade onde eu morava, em } \\
\text { Candiota, energia feita pelo carvão". } \\
\text { "Eu conheço um lugar que a energia vem dos cata-ventos, tem vários que } \\
\text { são em Bom Jardim da Serra, eles são muito grandes" }\end{array}$ & $\begin{array}{c}\text { Parques eólicos: geração de } \\
\text { energia através de } \\
\text { aerogeradores }\end{array}$ \\
\hline
\end{tabular}

Fonte: Dos autores 
O vídeo de fechamento desta atividade iniciou explorando e contextualizando a principal fonte da energia elétrica local, acompanhado do funcionamento das usinas hidrelétricas. Nesta categoria, energia hídrica, os áudios evidenciaram o entendimento parcial dos alunos acerca da sua origem e distribuição. Sendo assim, construiu-se uma explicação a respeito do processo de transformação do movimento da água sobre as turbinas (energia cinética) em energia elétrica.

$\mathrm{Na}$ segunda categoria, os alunos sugeriram a energia fotovoltaica como uma alternativa de recurso para geração de energia elétrica. Desta forma, foi destacada a utilização das placas solares para a conversão da energia solar em térmica ou elétrica. Por fim, a terceira categoria abordou a energia eólica como opção para regiões com ventos fortes e constantes através da transformação do movimento das pás dos aerogeradores (energia mecânica) em energia elétrica, nos parques eólicos.

\section{Considerações finais}

O que pareceu, num primeiro momento, um problema quase intransponível se transformou num desafiador e frutífero trabalho. Pela impossibilidade de executar o planejamento inicial feito para atividades presencias, que seriam muitas e de diversas abordagens métodológicas, uma (re)adaptação das ações propostas foi realizada, tendo-se como resultado uma profícua troca de saberes entre as crianças e o grupo da Universidade. Como mencionado, apesar das dificuldades - principalmente do campo tecnológico - houve um grande engajamento, com participação da maioria das crianças.

Os resultados demonstram importantes compreensões acerca da conscientização ambiental, da ampliação dos conhecimentos e do desenvolvimento de um pensamento crítico acerca dos temas propostos: (a) cuidados com o meio ambiente, (b) resíduos sólidos e reciclagem, (c) recurso natural água, e (d) energias renováveis. Disso resulta a compreensão de que, em condições tecnológicas ideais, o formato remoto - assíncrono e síncrono - pode ser uma efetiva abordagem para discussões/construções de EA.

Neste ponto, é importante valorizar a coparticipação e o comprometimento das mães, pais e responsáveis. Para além de permitirem que as crianças usassem seus celulares/meios eletrônicos - e seus pacotes de dados - para as atividades do projeto, em muitas respostas era possível perceber nas vozes de fundo a ajuda que estavam dando para seus filhos e filhas. Essa participação efetiva na educação das crianças precisa ser exaltada. No final do processo, foi solicitado que as mães, pais e responsáveis avaliassem o trabalho realizado. No quesito participação na educação dos filhos, o depoimento de uma mãe merece registro:

A nossa maior dificuldade é a internet, que pega muito fraco. Mas ela [a filha] aproveitou bem. A energia elétrica ela ficou surpresa quando eu expliquei pra ela de onde vinha, ela ficou bem admirada da água, fez bastante pergunta como que é gerada a energia. 
Em consideração à menção sobre a dificuldade de acesso à internet, convém esclarecer que o número de participações foi variável, de acordo com cada atividade. O diálogo com a equipe diretiva e pedagógica do Programa Viver mantinha todos atentos de que estavam fazendo o que era possível ser feito no contexto do cenário de pandemia.

As falas dos responsáveis pelas crianças, a seguir, também são reveladoras das dificuldades, do engajamento e da importância do trabalho realizado.

A maior dificuldade que a gente encontra aqui em casa para realizar as atividades é a questão de tempo mesmo, porque a gente continua trabalhando normalmente, então o tempo que a gente tem pra disponibilizar pra auxiliar não é todo o tempo do dia. Mas a gente vai fazendo conforme vai conseguindo, às vezes demora alguns dias pra conseguir dar o retorno da atividade, e a gente fica bem contente que vocês estarem continuando o trabalho com as crianças. Enfim, eles também sentem falta do projeto, dos amigos, das profes e de todas as atividades e eu acho que esse contato, nem que seja por aqui [aplicativo de mensagens], acaba deixando eles ainda com esse vínculo. Então nós ficamos bem felizes, e a nossa dificuldade mesmo é a questão de tempo.

Nós também estamos colaborando o máximo que a gente pode, às vezes os horários são meio corridos. A gente trabalha fora também e não é fácil administrar e conseguir ajudar eles. Mas a gente dedica esse tempo pros nossos filhos pela importância que isso tem. A gente gosta muito do Programa Viver, do trabalho que vocês fazem pelas crianças. De antemão, estão sempre de parabéns por se preocuparem com nossos filhos e fazerem de tudo por eles. Obrigada!

Nós aqui em casa estamos colaborando o máximo possível para que o [cita o nome do filho] faça os trabalhos que estão mandando sobre o meio ambiente. A gente fica muito feliz de participar e poder estar ajudando. Obrigada vocês por esse vínculo com as crianças.

Cabe o destaque final que, ainda que não se tenha conseguido avançar para as etapas $4 \mathrm{e}$ 5 (Quadro 1), sugeridas por Alves (2001), foi possível perceber um senso de responsabilidade e criticidade quanto ao modo de as crianças participantes se relacionarem, individual e coletivamente, com o meio ambiente, no âmbito do contexto em que estão inseridas (casa, escola e cidade).

\section{Referências}

ALVES, F. L. Educação Ambiental e Educação para a Cidadania. Olam - Ciência e Tecnologia, Rio Claro, v.1, n.1, p. 160-175, ago. 2001.

BARDIN, Laurence. Análise de Conteúdo. Lisboa: Edições 70, 1977. 
BIANCHINI, D. C.; FANK, J. C.; SEBEN, D.; RODRIGUES, P.; RODRIGUES, A. C. Sustentabilidade e Educação Ambiental na Escola Estadual de Ensino Fundamental Waldemar Sampaio Barros. Revista do Centro de Ciências Naturais e Exatas, UFSM. Santa Maria, ed. esp. p. 188-194, 2015.

BRASIL. Lei no 9.795. Dispõe sobre a educação ambiental, institui a Política Nacional de Educação Ambiental e dá outras providências. Diário Oficial da União, Brasília, 28 abr. 1999.

BRASIL. Decreto no 4.281, de 25 de junho de 2002. Regulamenta a Lei ${ }^{\circ} 9.795$, de 27 de abril de 1999. Diário Oficial da União, Brasília, 26 jun. 2002.

FRANÇA, P. A. R.; GUIMARÃES, M. G. V. A educação ambiental nas Escolas Municipais de Manaus (AM): um estudo de caso a partir da percepção dos discentes. Revista Monografias Ambientais - REMOA, v. 14, n. 2, p. 3128-3138, mar. 2014.

GUIMARÃES, M. Educação ambiental crítica. In: LAYRARGUES, P. P. (Coord.). Identidades da Educação Ambiental Brasileira. Brasília: Ministério do Meio Ambiente, 2004. p.25-34.

HANSEN, K. S. Metodologias de ensino da educação ambiental no âmbito da educação infantil. Educação Ambiental em Ação, v. 11, n. 43, 2018.

LOUREIRO, C. F. B. Educação ambiental e gestão participativa na explicitação e resolução de conflitos. Gestão em Ação, Salvador, v.7, n.1, jan./abr. 2004.

MEDEIROS, A. B. D.; MENDONÇA, M. J. S. L.; SOUSA, G. L. D.; OLIVEIRA, I. P. D. A importância da educação ambiental na escola nas séries iniciais. Revista Faculdade Montes Belos, v. 4, n. 1, set. 2011.

MOITINHO, E. B.; CAMPOS, G. M.; MACHADO, I. B.; FIGUEREDO, D. M.; MENDES, I. M. F.; SALES, R. M. M. A educação ambiental como instrumento de sensibilização para reutilização de resíduos sólidos. Revista Verde de Agroecologia e Desenvolvimento Sustentável, v. 12, n. 5, p. 874-878, 2017.

MORAES, R. Análise de conteúdo. Revista Educação, Porto Alegre, v. 22, n. 37, p. 7-32, 1999. 
RAMOS, E. C. Educação ambiental: origem e perspectivas. Educar, Curitiba, n.18, p. 201$218,2001$.

SILVA, A.; MESQUITA, G.; SOUZA, M. Educação ambiental como paradigma para a construção da sustentabilidade. Revista Eletrônica em Gestão, Educação e Tecnologia Ambiental, Santa Maria, v. 19, n. 2, p. 1133-1140, maio/ago., 2015.

SORRENTINO, M.; TRAJBER, R.; MENDONÇA, P.; FERRARO JR, L. A. Educação Ambiental como Política Pública. Educação e Pesquisa, v. 31, n. 2, p. 285-299, maio/ago. 2005.

Notas

1. Animações usadas como elementos disparadores de cada atividade:

a) Cuidados com o Planeta Terra: https://www.youtube.com/watch?v=7vsHFj3z6Xg

b) Resíduos sólidos e reciclagem: https://www.youtube.com/watch? $\mathrm{v}=\mathrm{O}$ JsvzfLgKTw

c) Recurso natural água: https://www.youtube.com/watch?v=Iye8mZexCSM; https://www.youtube.com/watch?v=7eGrzqHPZCo

d) Energias renováveis: https://www.youtube.com/watch?v=uSQ05nadYJo\&t=6; $\mathrm{https}: / / \mathrm{www}$.youtube.com/watch? $\mathrm{v}=8 \mathrm{DVtAW} 3 \times \mathrm{Nx} 8$

2. O áudio e os vídeos produzidos por meio das categorias emergentes de cada temática de estudo não foram aqui disponibilizados, a fim de se preservar a identidade (voz) das crianças. 